\title{
Characterization of Shear Strength of FRP Anchors
}

\author{
Philipp Mahrenholtz ${ }^{1, *}$, Jae-Yeol $\mathrm{Cho}^{2}$, Ja-Min Park ${ }^{2}$, and Rolf Eligehausen ${ }^{3}$ \\ ${ }^{1}$ Stanley Black \& Decker, Dewalt Anchors, 60596 Frankfurt, Germany \\ ${ }^{2}$ Department of Civil and Environment Engineering, Seoul National University, Seoul 151-744, Korea \\ ${ }^{3}$ Department for Civil and Environmental Engineering, University of Stuttgart, 70569 Stuttgart, Germany
}

\begin{abstract}
A critical performance aspect of FRP retrofitted concrete elements is the bonding of the FRP sheet to the concrete surface. In general, the performance is limited by the debonding of the loaded FRP sheets from the concrete surface. One method to delay debonding and enhance the capacity is the use of FRP anchors which interlock the FRP sheet to the concrete body. FRP anchors are made of rolled FRP fibres epoxied into in predrilled boreholes. There are a considerable number of studies on FRP strengthening methods available, and also FRP anchors attract more attention of the research community recently. However, to date FRP anchors were tested in a system together with the FRP sheet attached to the concrete, inhibiting the development of general design models. Moreover, the anchor behaviour was never tested for cyclic loads, though most applications are for seismic retrofitting schemes and cyclic shear loading generally results in reduced load capacity due to fatigue failure. To overcome the deficit in knowledge, shear tests on various FRP anchors were carried out. For these tests, FRP anchors were installed in concrete specimens on a separating steel section. The FRP anchor was then directly loaded to determine the capacity of the isolated component. This paper describes the testing approach and procedure. Details on the experimental results for static tests are presented and an outlook on seismic tests is given.
\end{abstract}

\section{Introduction}

A properly designed and durable anchorage of the FRP laminates to the concrete is critical for the performance of FRP strengthened concrete to avoid failure before the assigned load capacity is reached. Anchoring is in the first place provided by direct bonding of the laminates to the concrete, for which either resin or adhesives is applied. However, the bond strength transferable from the laminates to the concrete is limited and therefore the strength of the strips and fabrics is only utilized to a

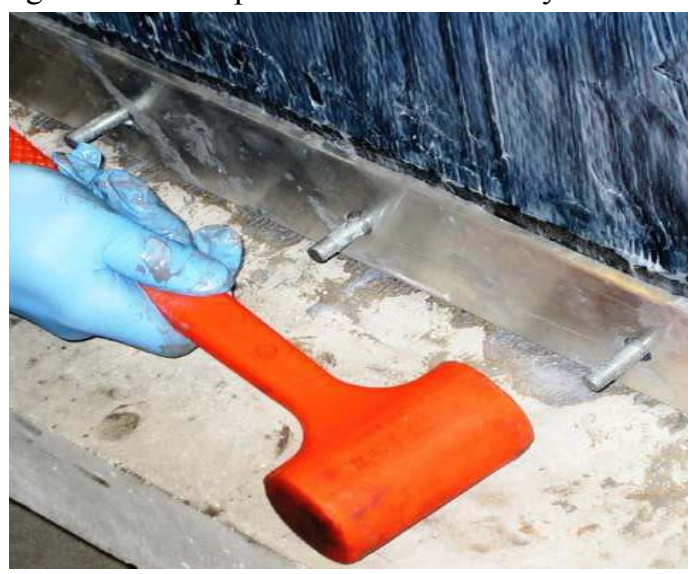

Fig. 1. End plate anchored by metal anchors (courtesy A. Mofidi [3]). small degree (e.g. [1], [2]). To transfer large forces, additional anchorage is required (Figure 1).

The use of post-installed metal anchors (Figure 2, left) is straightforward but also has some disadvantages. The anchors penetrate and cut the carbon fibres resulting in a substantial weakening of the laminate. Further, the unavoidable gap between the anchor and laminate requires the laminate to slip before the anchor is activated, leading de facto to a partial delamination. Moreover, variable annular gaps result in unequal load

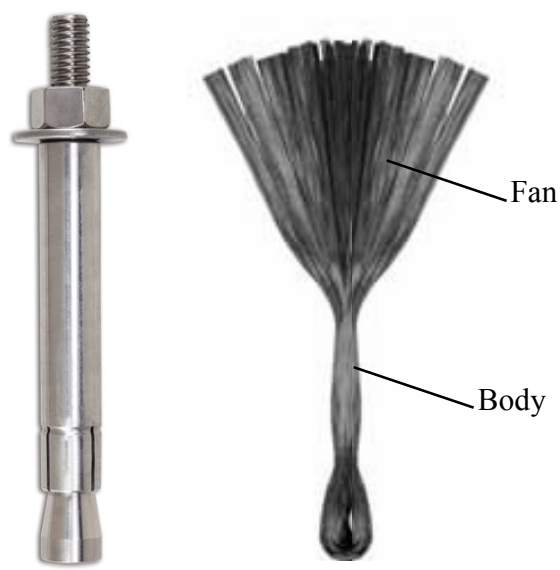

Fig. 2. Examples of commercially available metal anchor (left) and FRP anchor made of carbon fibre (right).

* Corresponding author: philipp@mahrenholtz.net 
distribution within anchor groups and increased stress for individual anchors. An alternative to mechanical anchors are FRP anchors which are made of tailored and rolled carbon fibre bundles (Figure 2, right). FRP anchors, also often called spike anchors, are cheap and their installation is flexible and easy. The FRP laminates do not have to be costly furnished with disadvantageous installation holes. The load is directly transferred from the FRP laminate via the integrated FRP anchor to the base material. So this anchorage solution does not rely on pre-stressing of anchors and all anchors are engaged already at low load levels.

To date, most of the studies involving FRP anchors have been carried out on FRP strengthened concrete elements, allowing the evaluation of the performance of FRP anchors as part of the structural system. Test results clearly showed that the capacity of FRP strengthened reinforced concrete structures can be substantially increased when early delamination is prevented by FRP anchors [4]. However, the design and application of the FRP anchors used in these studies are so specific that general conclusions on the anchor capacity cannot be drawn and it was concluded that more tests for characterizing anchor performance are needed [5].

To investigate the capacity of isolated FRP anchors, several studies were conducted on FRP anchors loaded in tension (e.g. [6], [7]) and it was shown that FRP anchors could be designed in tension similar to design rules existing for metal anchors [8]. However, experimental studies on FRP anchors loaded in shear are explicitly recommended in order to evaluate their strength and to enable the development of design models ([9], [10]). To close this gap, the experimental study presented in this contribution investigated the ultimate load capacity of isolated FRP anchors loaded in shear and identified the key parameter influencing the strength. The tests conducted on FRP anchors installed in concrete prisms and loaded in shear to failure then allowed developing a shear strength model.

\section{Experimental programme and details}

\subsection{Test setup}

For the tests, FRP anchors of variable configuration were installed in concrete prisms and epoxied to a steel channel which was furnished with a $20 \mathrm{~mm}$ hole to let the anchor body pass through (Figure 3). The steel channel was a C-section $75 \times 40 \times 4 \mathrm{~mm}$ and $420 \mathrm{~mm}$ long. It served as a load transfer device and separated anchor and concrete. The prisms were made of concrete with a nominal compressive strength of $f_{c}{ }^{\prime}=25 \mathrm{MPa}$. The size of the concrete prism was $150 \times 150 \mathrm{~mm}$ in cross section, and $300 \mathrm{~mm}$ in height and thereby large enough to allow concrete stresses to develop freely during shear loading without the influence of concrete edges. For the matrix epoxy, a two-component epoxy primer was chosen for its low viscosity and high bond strength of $1.5 \mathrm{MPa}$.
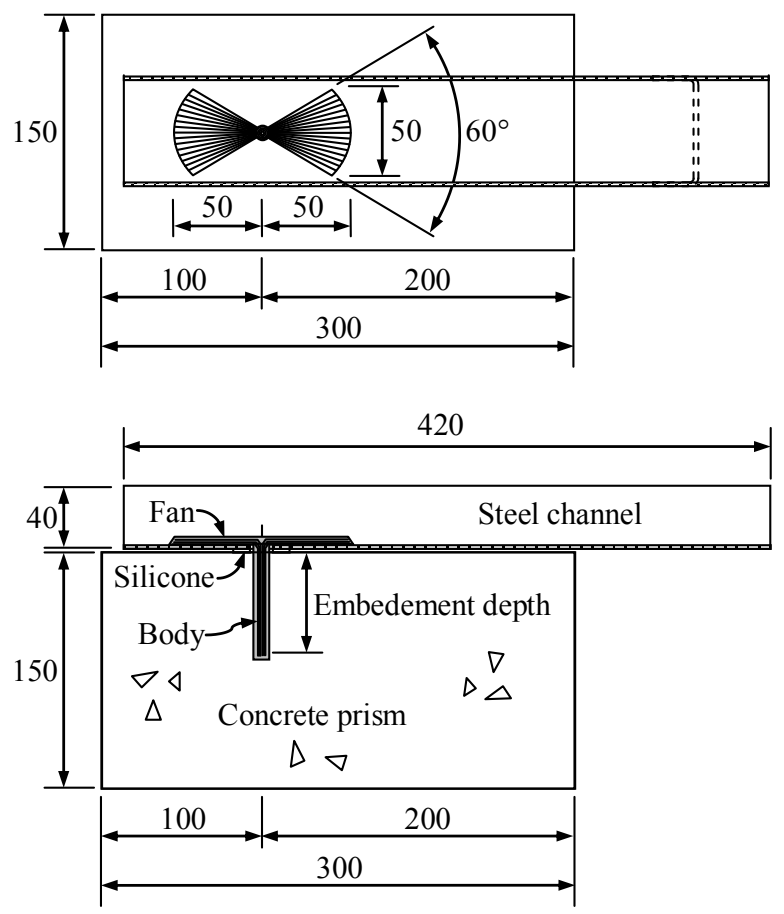

Fig. 3. Specimen geometry and details (units in mm): Plan (top) and elevation (bottom).

For the FRP anchor, a hole was drilled in the concrete prism with an embedment between 60 and $120 \mathrm{~mm}$, depending on the test series. The steel channel was positioned with its hole directly over the anchor hole. The annular gap between steel section and concrete surface was sealed with silicone. The anchor hole in the concrete prism was then filled with epoxy. After insertion of the anchor body, the fibres of the anchor fan were spread over the steel channel and additional epoxy was applied to form the anchor fan. After 4 days for curing, the test specimen was ready for testing.

The test specimen was then mounted in a universal testing machine (UTM) (Figure 4). The concrete prism was clamped in a strong steel cage which bottom plate was gripped by the bottom jaw of the UTM. The steel channel, protruding the top plate of the cage, was gripped by the upper jaw of the UTM. This test setup allowed to loading the specimen not only in tension but also in compression. More details on the test setup can be found in [11].

\subsection{FRP anchors}

Place FRP anchors were made of a uni-directionally woven carbon fibre material with a specified tensile strength of $4800 \mathrm{MPa}$ at $2 \%$ ultimate strain. The fibre roving was cut into sheets of variable length and width. The length corresponds to the embedment depth of the anchor body plus the radial length of the projected fan. The width defines the fibre content of the anchor in cross section (Figure 5). The width of fibre sheet was rolled by hand while keeping the fibres compressed together with regard to the envisaged diameter of the finished anchor. 


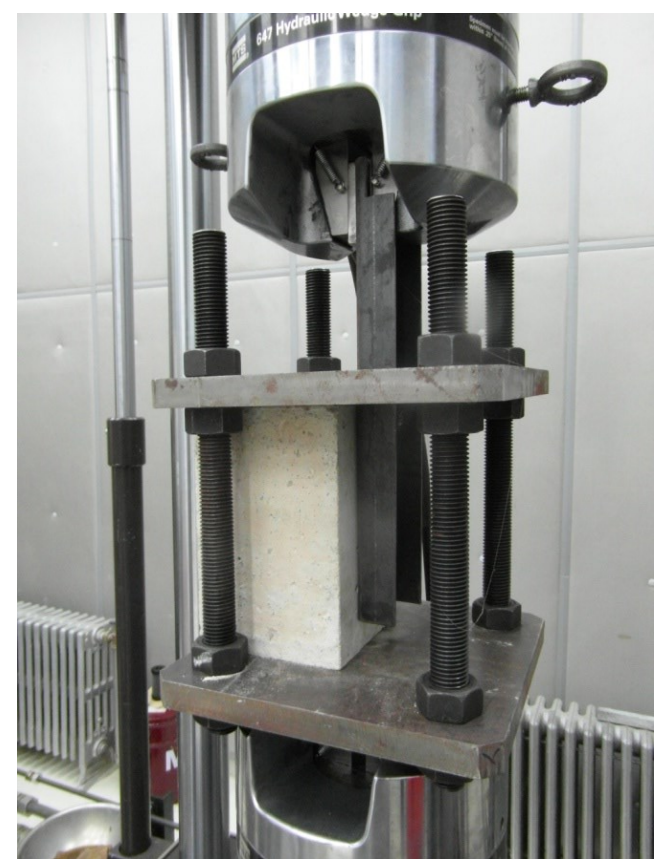

Fig. 4. Specimen mounted in testing machine.
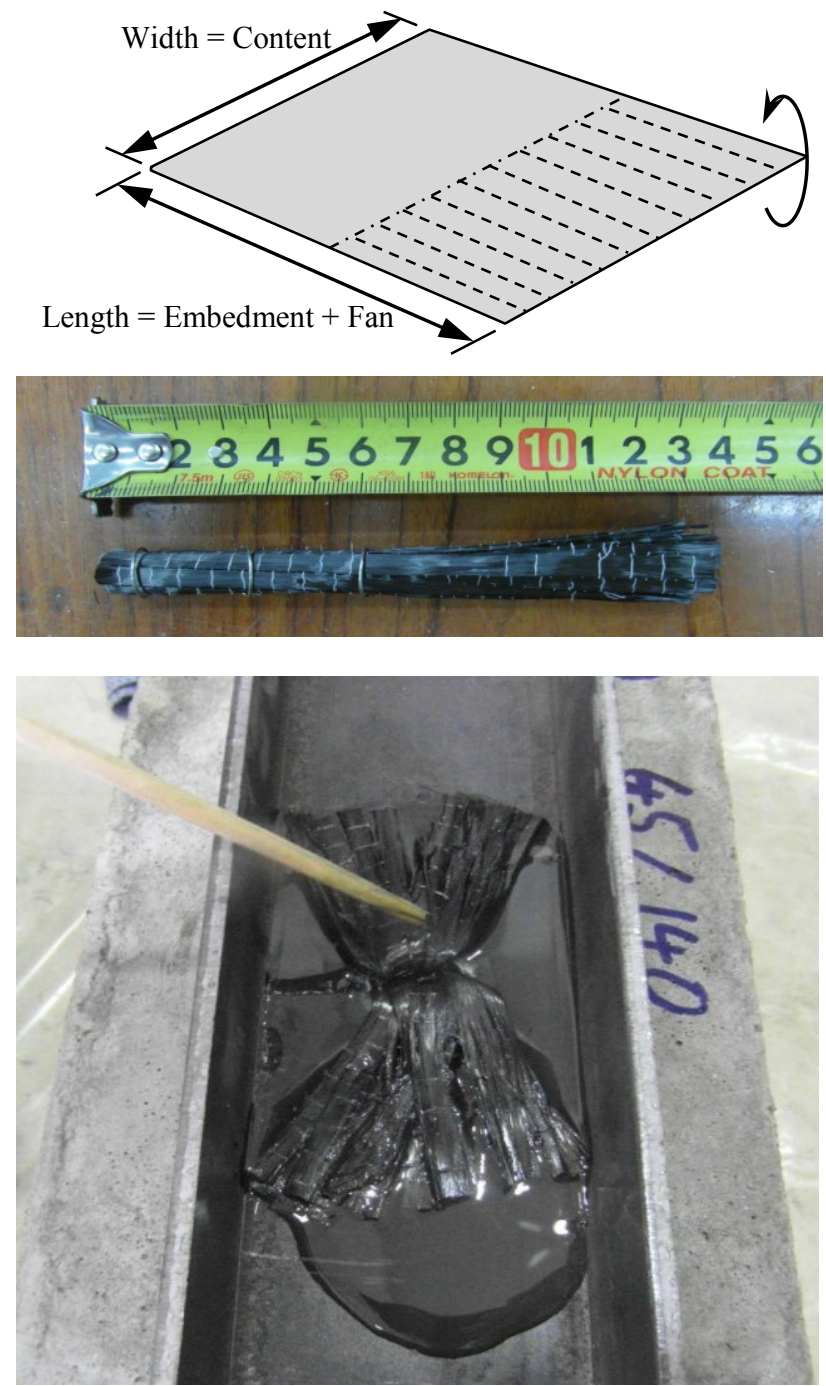

Fig. 5. Top: Schematic of anchor manufacturing; Mid: Finished anchor; Bottom: Installed anchor.
Earlier studies on FRP anchors have identified geometrical parameters that are critical for the performance of FRP anchors. Based on these findings, anchor diameter $d$ and fibre content $w_{f}$, as well as borehole diameter $d_{0}$ and embedment depth $h_{e f}$ were varied. The fan geometry was laid out with a fan width of $50 \mathrm{~mm}$ for a length of $50 \mathrm{~mm}$ resulting in a fan angle of $60^{\circ}$. In total, 25 tests were run which also included cyclic tests with reverse loading which are comprehensively discussed in [12]. In this paper, however, only the monotonic tests critical for the strength model are discussed. Relevant test parameters are summarized in Table 1.

Table 1. Selected test parameters.

\begin{tabular}{|c|c|c|c|c|c|}
\hline $\begin{array}{c}\text { Test } \\
\text { no. }\end{array}$ & $\begin{array}{c}\text { Fibre } \\
\text { content } \\
{[\mathbf{m m}]}\end{array}$ & $\begin{array}{c}\text { Embedm } \\
\text { Depth } \\
{[\mathbf{m m}]}\end{array}$ & $\begin{array}{c}\text { Anchor } \\
\text { diameter } \\
{[\mathbf{m m}]}\end{array}$ & $\begin{array}{c}\text { Borehole } \\
\text { diameter } \\
{[\mathbf{m m}]}\end{array}$ & $\begin{array}{c}\text { Annular } \\
\text { gap } \\
{[\mathbf{m m}]}\end{array}$ \\
\hline 1 & 100 & 60 & 10 & 12 & 2 \\
\hline 2 & 100 & 60 & 10 & 12 & 2 \\
\hline 3 & 100 & 60 & 10 & 12 & 2 \\
\hline 4 & 100 & 20 & 10 & 12 & 2 \\
\hline 5 & 100 & 45 & 10 & 12 & 2 \\
\hline 6 & 100 & 80 & 10 & 12 & 2 \\
\hline 7 & 100 & 60 & 12 & 12 & 0 \\
\hline 8 & 100 & 60 & 12 & 14 & 1 \\
\hline 9 & 100 & 60 & 12 & 16 & 2 \\
\hline 10 & 100 & 60 & 14 & 14 & 0 \\
\hline 11 & 100 & 60 & 16 & 16 & 0 \\
\hline 12 & 140 & 60 & 14 & 14 & 0 \\
\hline 13 & 180 & 60 & 16 & 16 & 0 \\
\hline
\end{tabular}

\section{Experimental results and discussion}

\subsection{Load-displacement behaviour and failure mode}

All tested anchors showed a very steady load response with a nearly linear ascending load branch (Figure 4a). The capacity of the FRP anchor with the used fibre content is relatively low as the pure shear strength of the FRP material is very low if compared to its outstanding tensile strength. After peak load, the anchor strength was rapidly reduced, indicating a pronounced brittle failure. All anchors ultimately failed by rupture of the fibres in the plane of the concrete surface (Figure 6). The fan remained undamaged and was not delaminated from the steel channel.

In anchor technology, which design is historically strictly load based, failure is assumed for the point of ultimate load, i.e. maximum load capacity. Ultimate shear load $V_{u}$ at peak and corresponding displacement $s\left(V_{u}\right)$ are indicated in Figure 6. 


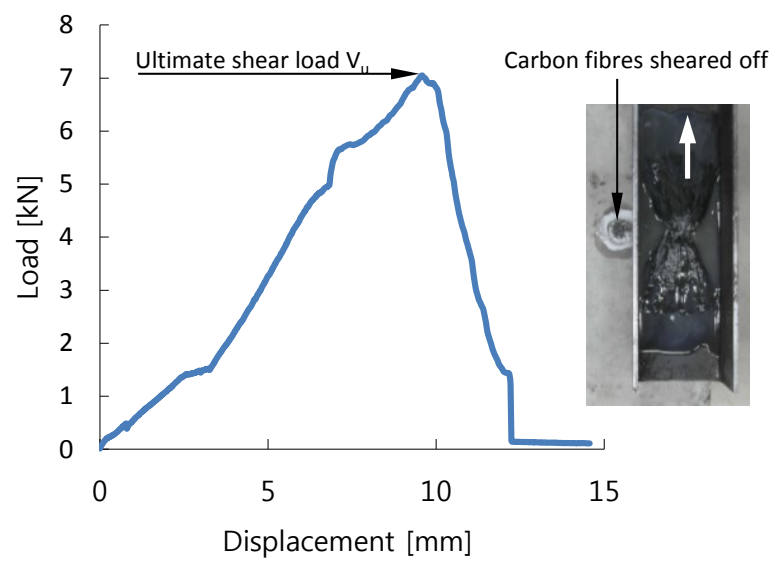

Fig. 6. Example of typical load-displacement curve and picture of failure.

\subsection{Ultimate capacity and influencing parameters}

In total, 24 shear tests were carried out. Table 2 lists key results of those tests which are relevant for the following discussion. The ultimate capacities for FRP anchors of same type and fibre content (test nos. 1 to 3 ) showed a relatively low scatter. The coefficient of variation of the mean ultimate load $V_{u, m}=6.6 \mathrm{kN}$ is $v\left(V_{u}\right)=6.7 \%$, which is in the range of what is typically measured for shear loaded metal anchors failing in steel. Tests with variable embedment depths of the FRP anchor did not have any significant impact on the load capacity but on the displacement capacity which increases with decreasing embedment.

Table 2. Key test results.

\begin{tabular}{|c|c|c|}
\hline $\begin{array}{c}\text { Test } \\
\text { no. }\end{array}$ & $\begin{array}{c}\text { Ultimate load } \\
\boldsymbol{V}_{\boldsymbol{u}} \\
{[\mathbf{k N}]}\end{array}$ & $\begin{array}{c}\text { Displacement } \\
\boldsymbol{s}\left(\boldsymbol{V}_{\boldsymbol{u}}\right) \\
{[\mathbf{m m}]}\end{array}$ \\
\hline 1 & 7.0 & 4.8 \\
\hline 2 & 6.2 & 3.6 \\
\hline 3 & 6.4 & 4.2 \\
\hline 4 & 6.6 & 9.1 \\
\hline 5 & 7.3 & 7.4 \\
\hline 6 & 5.7 & 3.2 \\
\hline 7 & 7.0 & 5.2 \\
\hline 8 & 7.4 & 6.1 \\
\hline 9 & 7.4 & 7.8 \\
\hline 10 & 6.6 & 5.8 \\
\hline 11 & 7.2 & 7.5 \\
\hline 12 & 9.0 & 5.4 \\
\hline 13 & 10.5 & 6.5 \\
\hline
\end{tabular}

For the other test series, the annular gap as well as fibre content and density were varied. Test 1 conducted on a FRP anchor with $100 \mathrm{~mm}$ fibre content and installed $60 \mathrm{~mm}$ deep served as baseline reference. It was installed in a $12 \mathrm{~mm}$ diameter hole with no annular gap. Variable annular gaps were created by installing FRP anchors of same diameter in boreholes of variable diameters. The results indicate that the gap, filled by epoxy only, did not affect the load capacity but the displacement capacity which increased for larger gaps. For the tests on variable fibre densities, FRP anchors of variable diameter were manufactured by rolling the fibre sheets more or less dense. The results show that also the fibre density was irrelevant for the load capacity, while the displacement capacity increases for decreasing fibre density. For the last test series on variable fibre content, the load capacity increased approximately linearly with increasing content, identifying the fibre content as the driving performance factor for FRP anchors loaded in shear. However, the displacement capacity only increased slightly for increasing fibre content.

\section{Model development}

The anchor design rules given in EN 1992 Part 4 [13] and ACI 318 [14] for metal anchors bases on the CCD method [15]. This rational method identifies that failure mode which yields the smallest capacity and therefore governs the anchor resistance, and distinguishes between tension and shear loading. Anchors loaded in tension may fail in steel, concrete, or pullout mode. Metal anchors loaded in shear generally fail in steel when not located close to any edge or not installed with very short embedment length. The steel capacity $V_{R k, s}$ of a metal anchor loaded in shear depends in the first place on the cross section As and the ultimate steel strength $f_{u k}$ :

$$
V_{R k, s}=\alpha \cdot A_{s} \cdot f_{u k}
$$

$\alpha$ is an empirically determined coefficient in the range of 0.5 to 0.7 relating the shear capacity to the tensile capacity $\left(A_{s} \cdot f_{u k}\right)$. The strict correlation of load capacity and fibre content found in the tests presented in this paper allows developing an equation similar to Eq. (1). Indexed for FRP anchors, this equation can be written to:

$$
V_{R k, f}=\alpha_{f} \cdot A_{f} \cdot f_{f, u k}
$$

With the thickness $t_{f}$ and a given content of fibres $w_{f}$, the cross-sectional area of carbon fibres $A_{f}$ can be calculated to:

$$
A_{f}=t_{f} \cdot w_{f}
$$

$f_{f, u k}$ is the characteristic ultimate strength of the fibre and $\alpha_{f}$ is an empirically determined coefficient basically relating tensile to shear strength of the installed fibre. Rearranging Eq. (2) and inserting Eq. (3) allows determining the $\alpha_{f}$ factor for a tested FRP anchor:

$$
\rightarrow \alpha_{f}=V_{R k, f} /\left(A_{f} \cdot f_{f, u k}\right)=V_{R k_{,}} /\left(t_{f} \cdot w_{f} \cdot f_{f, u k}\right)
$$

With a specified fibre density of $1.81 \mathrm{~g} / \mathrm{cm}^{3}$ and an area weight of $300 \mathrm{~g} / \mathrm{m}^{2}$, one can calculate the fibre sheet thickness to $t_{f}=300 \mathrm{~g} / \mathrm{m}^{2} / 1.81 \mathrm{~g} / \mathrm{cm}^{3}=165 \mathrm{~cm}^{3} / \mathrm{m}^{2}=$ $0.0165 \mathrm{~m}^{2} / \mathrm{m}^{2} \cdot \mathrm{cm}=0.165 \mathrm{~mm}$. The characteristic strength $f_{f, u k}$ can be taken as the tensile strength of 
$4800 \mathrm{MPa}$ specified by the manufacturer. Based on the mean ultimate load $V_{u, m}$ measured in a test series and its variation $v$, the characteristic shear capacity $V_{R k, f}$ of the FRP anchor may be estimated to:

$$
V_{R k, f}=V_{u, m}\left(1-k_{s} \cdot v\right)
$$

Taking the test series Specimen 1 to 3 with $V_{u, m}=$ $6.6 \mathrm{kN}, k_{s}=3.4(5 \%$-fractile, $90 \%$ confidence level), Eq. (5) yields $V_{R k, f}=6.6 \mathrm{kN}(1-3.4 \cdot 6.7 \%)=6.6 \mathrm{kN}$. $0.77=5.1 \mathrm{kN}$, and Eq. (4) results in $\alpha_{f}=5.1 \mathrm{kN} /$ $\left(0.165 \mathrm{~mm} \cdot 100 \mathrm{~mm} \cdot 4800 \mathrm{~N} / \mathrm{mm}^{2}\right)=0.06$. That means that for the specific FRP anchors considered, the shear capacity corresponds to $6 \%$ of the tensile capacity. This ratio is approximately one tenth of that typical for metal anchors; however, this disadvantage has to be balanced against the technical and cost advantage of FRP anchors.

\section{Conclusions}

Experimental tests carried out on FRP anchors allowed quantifying the shear load capacity of isolated FRP anchors, resulting in the following conclusions:

- The test setup used for this study proved to be practical and provided shear strength data with relatively low scatter.

- Driving parameter for the shear load capacity is the fibre content, i.e. fibre cross section in shear plane. The shear capacity increases approximately linearly with content.

- The shear load capacity can be described by a simple design equation similar to that used for metal anchors loaded in shear and failing in steel.

- The proposed shear strength design formula together with a first estimate for the $\alpha_{f}$ factor completes design models already existing for FRP anchors loaded in tension.

The German Academic Exchange Service (DAAD) granted a post-doctoral scholarship for the first author. In addition, the Integrated Research Institute of Construction and Environmental Engineering at Seoul National University provided additional funding. This support is gratefully acknowledged. The students of the Seoul National University (SNU) Laboratory are thanked for their assistance.

\section{References}

1. C. Triantafillou, N.Deskovic,, M. Deuring, Strengthening of concrete structures with prestressed fiber reinforced plastic sheets, ACI Str. J., 89(3): 235-244 (1992)
2. M. Deuring, Strengthening of RC with prestressed fiber reinforced plastic sheets, EMPA Research Report No. 224, Switzerland (in German) (1993)

3. A. Mofidi, O. Chaallal, B. Benmokrane, K. Neale, Performance of end-anchorage systems for RC beams strengthened in shear with epoxy-bonded FRP, ASCE J. of Comp. for Constr., 16: 322-331 (2010)

4. Y. Kim, K. Quinn, C. Satrom, W. Ghannoum, J. Jirsa, Shear strengthening RC T-beams using CFRP laminates and anchors, ACI SP (2011)

5. G. Huaco, J. Jirsa, O. Bayrak, Quality control test for carbon fiber reinforced polymer (CFRP) anchors for rehabilitation, ACI SP (2011)

6. G. Ozdemir, A. Ugurhan, Tensile capacity of CFRP Anchors. Nato Science Series Advances in Earthquake Engineering for Urban Risk Reduction, 66: 471-487 (2006)

7. T. Ozbakkaloglu, M. Saatcioglu, Tensile behavior of FRP anchors in concrete. ASCE J. of Comp. for Constr., 13(2): 82-92 (2009)

8. S.-J. Kim, S. Smith, Pullout strength models for FRP anchors in uncracked concrete. ASCE J. of Comp. for Constr., 14(4): 406-414 (2010).

9. S. Grelle, L. Sneed, An evaluation of anchorage systems for fiber-reinforced polymer (FRP) laminates bonded to reinforced concrete elements, Proceedings of 2011 ASCE Structures Congress. Las Vegas, p.14-16 (2011)

10. R. Kalfat, R. Al-Mahaidi, S. Smith, Anchorage devices used to improve the performance of reinforced concrete beams retrofitted with FRP composites: A-State-of-the-Art-Review, ASCE J. of Comp. for Constr., 17(1): 14-33 (2013)

11. P. Mahrenholtz, J.-Y. Cho, Monotonic and Cyclic Behavior of Isolated FRP Anchors in Concrete. Report Registration No. 10200821509 of the Seoul National University (2013)

12. P. Mahrenholtz, J.-Y. Cho, J.-M. Park, Monotonic and cyclic behaviour of isolated FRP anchors loaded in shear, Comp. Part B: Eng. J., 72, 72-79 (2015)

13. EN 1992. Eurocode 2: Design of concrete structures. Brussels, European Committee for Standardization (CEN), (2011)

14. ACI 318. Building code requirements for structural concrete (ACI 318-14) and commentary. Farmington Hills, American Concrete Institute (ACI), (2014)

15. W. Fuchs, R. Eligehausen, J. Breen, Concrete Capacity Design (CCD) Approach for fastening to concrete, ACI Str. J., 92(6): 73-94 (1995) 